\title{
Some bio-optical characteristics of phytoplankton in the NW Indian Ocean
}

\author{
Shubha Sathyendranath ${ }^{1,2, *}$, Trevor Platt ${ }^{2}$, Venetia Stuart ${ }^{1}$, Brian D. Irwin ${ }^{2}$, \\ Marcel J. W. Veldhuis ${ }^{3}$, Gijsbert W. Kraay ${ }^{3}$, W. Glen Harrison ${ }^{2}$ \\ 'Department of Oceanography, Dalhousie University, Halifax, Nova Scotia, Canada B3H 4J1 \\ ${ }^{2}$ Biological Oceanography Division, Bedford Institute of Oceanography, Box 1006, Dartmouth, Nova Scotia, Canada B2Y 4 A2 \\ ${ }^{3}$ Netherlands Institute for Sea Research, PO Box 59, 1790 AB Den Burg, Texel, The Netherlands
}

\begin{abstract}
Light absorption by phytoplankton and the parameters of the photosynthesis-light curve were measured in the NW Indian Ocean in January to February 1993. The light absorption characteristics of phytoplankton show some regional differences, probably reflecting changes in the phytoplankton population: cyanobacteria (Synechococcus spp.) were present in all 3 regions and dominated the phytoplankton biomass in the Somali Current area; prochlorophytes were mainly confined to samples from the Somali Current area; and larger algal species, including diatoms, were found in the Red Sea and Gulf of Aden. The initial slope $a^{B}$ and the assimilation number $P_{m}^{B}$ of the photosynthesis-light curve had dynamic ranges of 3.7 and 3.9 , respectively, and appeared to be correlated with environmental co-variables such as nutrient concentrations and ambient light levels as well as phytoplankton absorption in the blue and red parts of the spectrum. Even though the sampling was confined to the mixed layer, there was some evidence of photoadaptation, suggesting that the rate of vertical mixing in the mixed layer was rather slow, compared with photoadaptation rates. The quantum yield of photosynthesis varied over a factor of 6 , and was correlated with relative changes in absorption in the blue and red parts of the spectrum. The implications of these results for computation of primary production using photosynthesis-light models are discussed, with special reference to applications of remotely sensed data on ocean colour.
\end{abstract}

KEY WORDS: Bio-optical characteristics Phytoplankton - Light absorption . NW Indian Ocean Quantum yjeld

\section{INTRODUCTION}

The NW Indian Ocean, with its seasonally reversing patterns in winds and currents, is known to exhibit dramatic, temporal and spatial variations in the distribution of phytoplankton biomass and productivity (Yentsch 1965, Banse \& McClain 1986, Brock et al. 1991, Sathyendranath et al. 1991).

Our ability to model the primary productivity in this region, using light-dependent models of photosynthesis and satellite-derived data on phytoplankton biomass, is limited by lack of information on the photosynthetic characteristics (parameters of the photosyn-

\footnotetext{
•E-mail: shubha@ac.dal.ca
}

thesis-light, or the $P_{-} I$, curve) of the phytoplankton populations here (Brock et al. 1994). Even though we know very little about these parameters for the Indian Ocean region, there are, nevertheless, some indications that changes in these physiological parameters in response to the availability of nutrients could play a more central role in the generation of blooms there than in the initiation of spring blooms in the N Atlantic (Sathyendranath \& Platt 1994).

Another property of phytoplankton relevant to computations of water-column primary production is the absorption coefficient. The characteristics of light absorption by phytoplankton can be used to improve regional models of light transmission for use in primary production models. These properties are also required in the implementation of models of photosynthesis 
based on absorbed light rather than available light (Kiefer \& Mitchell 1983, Bidigare et al. 1987, Marra \& Heinemann 1987, Bidigare et al. 1992). In addition, variations in the specific absorption coefficient of phytoplankton affect the relationship between ocean colour and phytoplankton biomass. Therefore, local information on absorption characteristics of phytoplankton can be used to develop regional models of ocean colour for application in algorithms for retrieval of phytoplankton biomass from remotely sensed data.

Models of primary production based on absorbed light also require information on the maximum realised quantum yield of photosynthesis, a quantity that is often not available, since it calls for simultaneous measurements of both light absorption by phytoplankton and the parameters of the $P-I$ curve.

As a contribution to consolidation of the knowledge base useful for the estimation of primary production in the Indian Ocean, we present here some information from the NW Indian Ocean, collected during the NE monsoon period, on the spectral characteristics of light absorption by phytoplankton in the mixed layer. We show that the changes in the magnitude and shape of the chlorophyll-normalised absorption spectra are related to pigment composition and cell size. We also present data on $P-I$ parameters from the same stations and examine the factors responsible for variabilities in these parameters. These measured bio-optical properties are then used to compute the maximum realised quantum yield. Next, we show that changes in quantum yield reflect to a large extent variabilities in the species composition of phytoplankton. The implications of the results for computation of primary production using remotely sensed data on ocean colour are also discussed.

\section{MATERIALS AND METHODS}

Light absorption by phytoplankton and the $P-I$ parameters were measured during a cruise of the Dutch RV 'Tyro' to the NW Indian Ocean during the NE monsoon period of winter 1993 (January and February). Periods of strong NE winds caused relatively deep mixed layers with higher than normal nutrient levels and no deep chlorophyll maximum (Baars 1994). The sampled area covered 3 regions: the western Somali Current area, the Gulf of Aden and the Red Sea (see Fig 1). Samples were collected at 3 depths at each station: 4,10 and $40 \mathrm{~m}$. Concentrations of nutrients (nitrate, nitrite, phosphate and silicate) were measured on board using a TRAACS 800 auto-analyser, and chlorophyll a (chl a) concentrations were determined with a Turner Design fluorometer. The penetration of photosynthetically active radiation (PAR) was also measured at these stations.

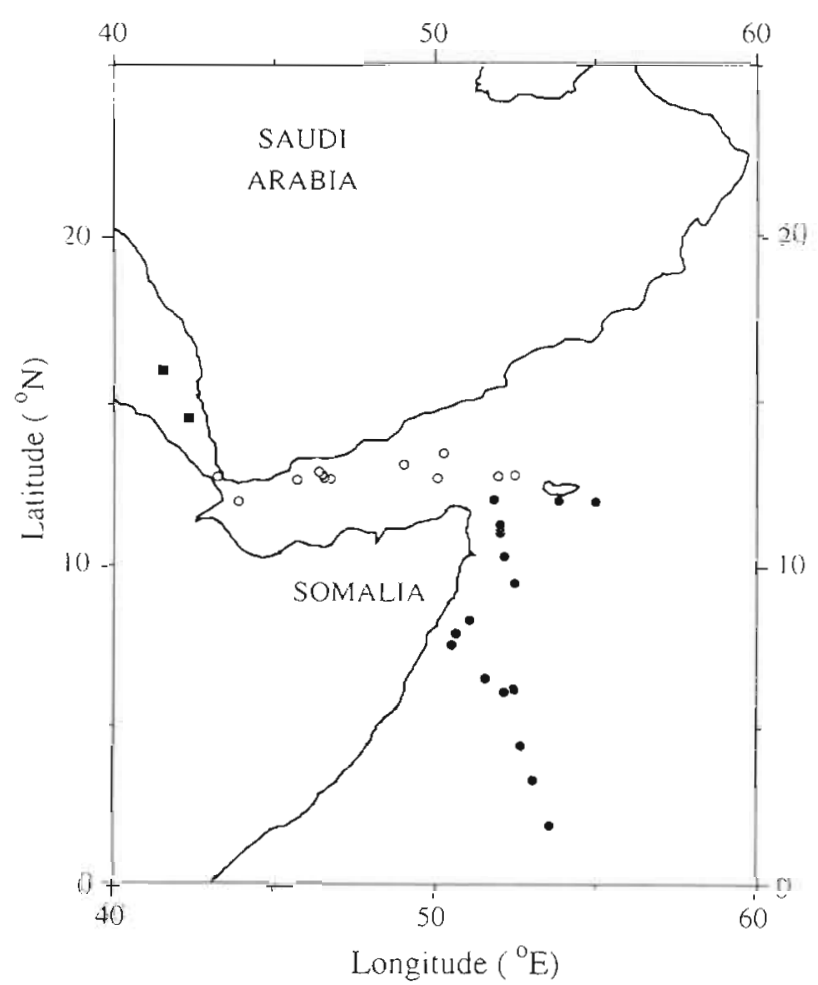

Fig. 1. Map showing the positions of sampling stations in the Somali Current area ( $\bullet$ ), the Gulf of Aden (o) and the Red Sea (-)

Some 68 samples were collected during the cruise, of which all but 3 fell in the mixed layer. The 3 samples from below the mixed layer were excluded from the analysis, and only the 65 samples from the mixed layer are presented and discussed in this paper.

The details regarding the bio-optical measurements are given below.

Measurement of light absorption by phytoplankton. Samples were collected on GF/F glass-fibre filters, and stored at $-70^{\circ} \mathrm{C}$ during the cruise. After the cruise, they were air-lifted to the laboratory in a deep freeze. Light absorption by total particulate material $\left[a_{p}(\lambda)\right.$, where $\lambda$ is the wavelength, $400 \mathrm{~nm} \leq \lambda$ $\leq 750 \mathrm{~nm}$ ] was measured in the laboratory on a spectrophotometer, using the filter technique of Yentsch (1962), as modified by Mitchell \& Kiefer (1984, 1988). The absorption by photosynthetic pigments $a_{c}(\lambda)$ was obtained from $a_{p}(\lambda)$ by subtracting absorption by detritus $a_{d}(\lambda)$, according to Kishino et al. (1985). The measurements were corrected for pathlength amplification due to scattering by the filter (Hoepffner \& Sathyendranath 1992, 1993). Each absorption spectrum of photosynthetic pigments was decomposed into 13 Gaussian bands representing absorption by the major phytoplankton pigments (chls $a, b$ and $c$, and carotenoids), as in Hoepfiner \& 


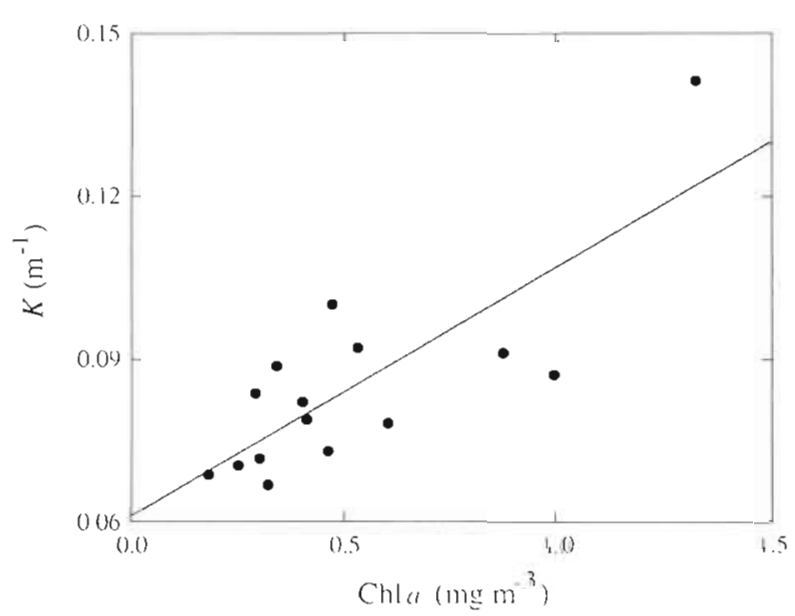

Fig. 2. Computed values of the attenuation coefficient, $K^{r}$, as a function of chl a concentration

Sathyendranath $(1991,1993)$. The Gaussian decomposition was carried out using the software package 'Peakfit' from Jandel Inc. The specific absorption coefficient relative to chl $a\left(a_{c}^{*}\right)$ was determined by dividing the total absorption coefficient at each wavelength by $B$, the chl a concentration determined fluorometrically using the Turner design fluorometer The Gaussian peak heights of the red and blue bands associated with chl $a, p(435)$ and $p(676)$ (with respective peak centres at around 435 and $676 \mathrm{~nm}$ ) were divided by chl a to obtain the specific peak heights, designated $p^{*}(435)$ and $p^{*}(676)$, respectively.

Parameters of the $P-I$ curve. Samples from each depth were incubated for 2 to $3 \mathrm{~h}$ at in situ temperatures under 30 irradiance levels $\left(1.2\right.$ to $\left.570 \mathrm{~W} \mathrm{~m}^{-2}\right)$. Primary production per hour, normalised to the biomass $B$, was estimated by the ${ }^{14} \mathrm{C}$ method for each incubation, and the results fitted with the equation of Platt et al. (1980) to determine the parameters $P_{m}^{B}$ (the assimilation number), $\alpha^{B}$ (the initial slope), $\beta^{B}$ (the photoinhibition parameter), and $R^{B}$ (the dark respiration). Fluorometrically measured chl a concentration was used as the index of biomass $B$.

Light penetration. Light penetration was measured using a Licor quantum meter measuring PAR. Measurements were made at $5 \mathrm{~m}$ intervals over the photic zone at local noon $\pm 1 \mathrm{~h}$. A comparable deck unit was used to correct the measurements for changes in incoming solar radiation. Average values of attenuation coefficient $K$ for the photic zone were computed for each station by regression of log-transformed light on depth $z$. The computed values of $K$ $\left(\mathrm{m}^{-1}\right)$ are plotted against chlorophyll concentration in Fig. 2 for the stations where light penetration was measured. Despite the fact that the chlorophyll samples were collected approximately $6 \mathrm{~h}$ earlier in the day, there was nevertheless a significant correlation $(\mathrm{p}<0.01)$ between $K$ and chlorophyll concentration. Linear regression yielded $K=0.061+$ $0.046 B\left(n=15, r^{2}=0.63,2\right.$ outliers omitted), very similar to the results reported by Tilzer et al. (1994) for the Northern Weddel Sea. This fitted equation was used to estimate $K$ at all the stations from $B\left(\mathrm{mg} \mathrm{m}^{-3}\right)$, which was then used to compute $I_{z}$, the percentage light available at the sampling depths, using the equation $I_{z}=100 \exp (-K z)$.

\section{RESULTS}

\section{Light absorption by phytoplankton}

Examination of the absorption spectra from the Somali Current area, the Gulf of Aden and the Red Sea showed some systematic differences. These differences may be associated with changes in species composition (Table 1): Synechococcus-type cyanobacteria were numerically the most abundant group in all 3 regions but also dominated the phytoplankton assemblage in the Somali Current area in terms of biomass (Veldhuis unpubl. data), prochlorophytes were most numerous in the Somali Current area, large eukaryotes (including diatoms) were most abundant in the Red Sea, while the Gulf of Aden had a mixed assemblage of small and large cells. These differences imply a change not only in pigment composition, but also in cell size, and both factors can affect the characteristics of light absorption by phytoplankton (Sathyendranath et al. 1987).

Changes in the concentrations of auxiliary pigments relative to chl a can lead to modifications in the shape of the absorption spectrum and to differences in the magnitude of absorption when the absorption spectra are normalised to chl a concentration. Changes in the optical density of cells modify the absorption spectra further: when a certain amount of pigment is distrib-

Table 1. Phytoplankton composition in the Somali Current Area, the Gulf of Aden and the Red Sea showing numbers of cells $\mathrm{ml}^{-1}( \pm 1 \mathrm{SD})$ for cyanobacteria, prochlorophytes, small eukaryotes $(<3 \mu \mathrm{m})$, medium eukaryotes ( 3 to $5 \mu \mathrm{m})$ and large eukaryotes (>5 $\mu \mathrm{m})$

\begin{tabular}{|lccc|}
\hline & Somali Current & Gulf of Aden & Red Sea \\
\hline Cyanobacteria & $48779 \pm 29013$ & $79128 \pm 29351$ & $35411 \pm 6546$ \\
Prochlorophytes & $49160 \pm 29563$ & $14248 \pm 7376$ & $1514 \pm 729$ \\
Small eukaryotes & $4626 \pm 2548$ & $6901 \pm 2173$ & $2543 \pm 4745$ \\
Medium eukaryotes & $6467 \pm 3822$ & $3874 \pm 3368$ & $5659 \pm 714$ \\
Large eukaryotes & 0 & $521 \pm 741$ & $1685 \pm 759$ \\
\hline
\end{tabular}


uted in cells with high optical density (which may be due to large size or high intracellular pigment concentration), then the pigments will appear to have a lower absorption coefficient than when the same amount of pigments are contained in cells of low optical density. This is the well-known flattening effect (Duysens 1956, Kirk 1976, Morel \& Bricaud 1981). Since the flattening effect is a function of the optical density of the cells, it is a wavelength-dependent effect, being most pronounced at wavelengths of absorption maxima. In the following paragraphs we examine variations in the shape and magnitude of the absorption spectra and attempt to evaluate how changes in pigment concentration and cell size affect the observed optical properties. To this end we make use of the technique of decomposing the absorption spectra into Gaussian bands, each representing absorption by a major pigment.

\section{Shape of the absorption spectra}

The average spectra for the 3 depths and the 3 regions are shown in Fig. 3. These spectra are all normalised at $435 \mathrm{~nm}$ to compare the shapes of the spectra rather than their magnitudes.

Even though all these spectra are from the mixed layer, there are systematic differences with depth, in all 3 regions. Notably, the absorption at $400 \mathrm{~nm}$, relative to absorption at $435 \mathrm{~nm}$, is very high at $4 \mathrm{~m}$ compared with $40 \mathrm{~m}$ or even $10 \mathrm{~m}$. In fact, the ratio of absorption at $400 \mathrm{~nm}$ to that at $435 \mathrm{~nm}$ is, on an average, 0.993 at $4 \mathrm{~m}, 0.745$ at $10 \mathrm{~m}$, and 0.741 at $40 \mathrm{~m}$. This probably indicates higher concentrations of UV-protective pigments in the surface, suggesting that the cells were photoacclimating faster than they were mixing It is interesting to note that the blue absorption maximum is slightly shifted towards longer wavelengths in the Somali Current area compared with the other 2 regions, which is consistent with the presence of divinyl-chl a associated with prochlorophytes (see Hoepffner \& Sathyendranath 1992)

In the blue-green part of the spectrum $(500$ to $550 \mathrm{~nm}$ ), all 3 regions have similar absorptions, except at $40 \mathrm{~m}$, where the Red Sea samples show the highest absorption, followed by the Gulf of Aden.

At all depths, the red absorption peak (relative to the absorption at $435 \mathrm{~nm}$ ) is highest in the Red Sea, and lowest in the Somali Current area. If we consider that the specific absorption coefficient of phytoplankton in the red part of the spectrum is less affected by changes in pigment composition or in cell size than in the blue part, this relative change probably reflects changes in the magnitude of the specific absorption coefficient in the blue part of the spectrum, an issue that is examined next.
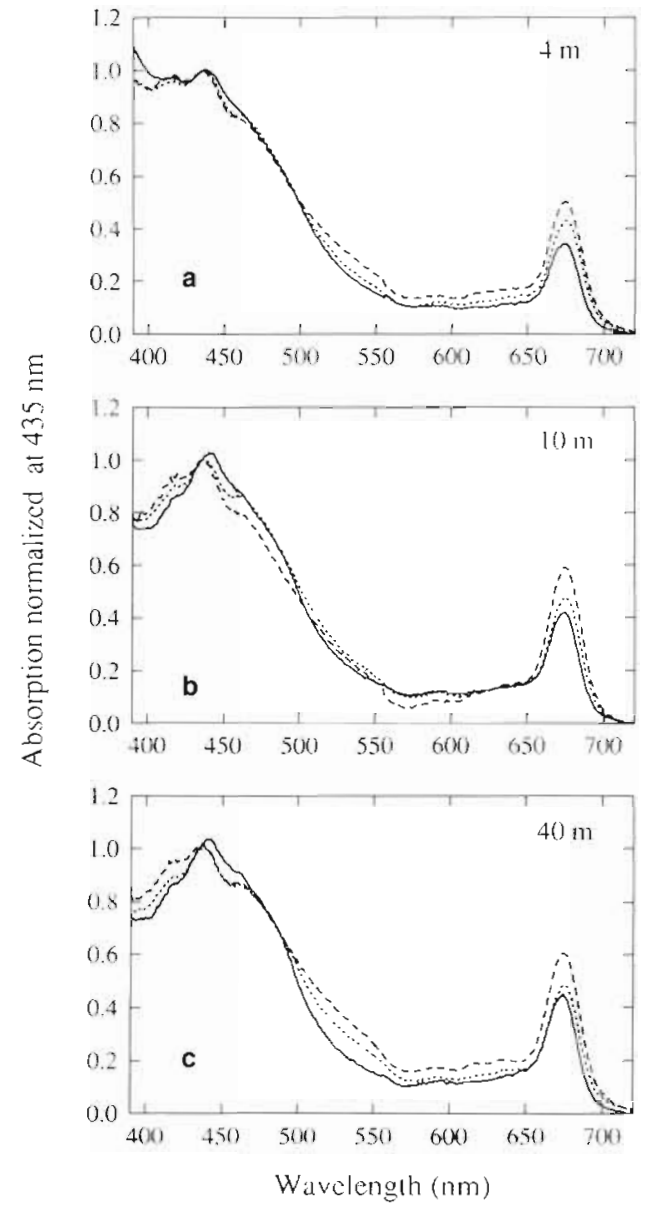

Fig. 3. Average absorption spectra normalized at $435 \mathrm{~nm}$ for samples from the Somali Current area (-), the Gulf of Aden (‥) and the Red Sea (---) for sampling depths (a) $4 \mathrm{~m}$, (b) $10 \mathrm{~m}$ and (c) $40 \mathrm{~m}$

\section{Light absorption at 435 and $676 \mathrm{~nm}$}

The specific absorption coefficient for each sample at $435 \mathrm{~nm}$ is plotted against the sample chl a concentration in Fig. 4 The figure shows that the pigment concentrations are lowest in the Somali Current area, and highest in the Red Sea. Phytoplankton from the low-chlorophyll, low-nutrient waters of the Somali Current area have the highest specific absorption at $435 \mathrm{~nm}$ [mean $0.086 \mathrm{~m}^{2}\left(\mathrm{mg} \mathrm{chl} \mathrm{a}^{-1}\right.$ ], compared with the Red Sea [mean $0.044 \mathrm{~m}^{2}(\mathrm{mg} \mathrm{chl} \mathrm{a})^{-1}$ ], with intermediate values in the Gulf of Aden [mean $0.073 \mathrm{~m}^{2}\left(\mathrm{mg} \mathrm{chl} \mathrm{a}^{-1}\right.$ ].

The differences between regions are consistent with our knowledge of the phytoplankton populations in these areas: the Red Sea, with large diatom cells, would be expected to have a lower specific absorption coefficient than the smaller prochlorophytes and cyanobacteria, if changes in cell size, rather than in intracellular pigment concentration, dominate the flattening effect. 


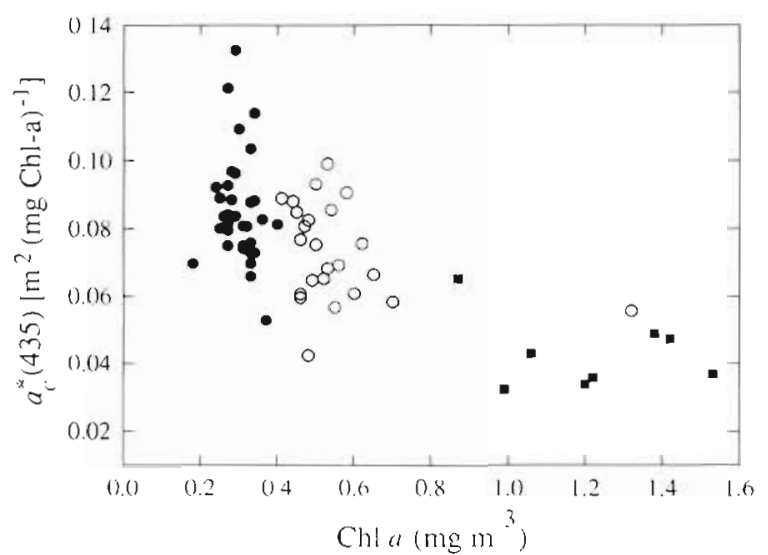

Fig. 4. Specific absorption coefficient at $435 \mathrm{~nm}$ as a function. of the chl a concentration for the Somali Current area $(\bullet)$, the Gulf of Aden (0) and the Red Sea ( ()

However, these changes in cell sizes are also accompanied by changes in pigment composition. For example, cyanobacteria are capable of harvesting light using phycobiliproteins rather than chlorophyllcarotenoid complexes (Cullen et al. 1993, Geider 1993) leading to increased specific absorption coefficients when the spectra are normalised to chl a concentrations. It is difficult, in a plot such as Fig. 4, to separate the effects of size and intracellular pigment concentration from that of pigment composition (Sathyendranath et al. 1987). In addition, samples from the Somali Current area exhibit some evidence of photoadaptation, with the highest specific absorption being found in the $4 \mathrm{~m}$ samples [mean $0.092 \mathrm{~m}^{2}$ (mg chl a) ${ }^{-1}$ ] compared with the 10 or $40 \mathrm{~m}$ samples $\left[0.083\right.$ and $0.078 \mathrm{~m}^{2}$ (mg chl a $)^{-1}$, respectively]. As cells become shadeadapted, the cellular concentration of the absorbing pigments increases (Geider et al, 1986, Falkowski \& LaRoche 1991). The increase in intracellular pigment concentrations could in turn lead to an increase in the flattening effect and a consequent decrease in specific absorption (Geider et al. 1986, Johnsen \& Sakshaug 1993). The depth-dependent changes in specific absorption imply a slower vertical mixing rate for the Somali Current area than the other 2 regions (see also Cullen \& Lewis 1988), or a faster photoadaptation rate for the Somali Current area population.

Since the flattening effect becomes more important at wavelengths of high absorption, one may anticipate that this effect would be smaller in the red than in the blue part of the spectrum. In fact, the specific absorption at $676 \mathrm{~nm}$ is relatively stable: the standard deviation in the specific absorption at this wavelength is low (0.006), around a mean of $0.032 \mathrm{~m}^{2}(\mathrm{mg} \text { chl a })^{-1}$. The regionally differentiated, mean, specific absorption coefficients at this wavelength are also less variable than at $435 \mathrm{~nm}$, ranging from $0.032 \mathrm{~m}^{2}(\mathrm{mg} \mathrm{chl} \mathrm{a})^{-1}$ in the Somali Current area and $0.033 \mathrm{~m}^{2}\left(\mathrm{mg} \mathrm{chl} \mathrm{a}^{-1}\right.$ in the Gulf of Aden to $0.024 \mathrm{~m}^{2}(\mathrm{mg} \mathrm{chl} \mathrm{a})^{-1}$ in the Red Sea. The specific absorption coefficients for the Somali Current area and the Gulf of Aden are high, compared with values reported in the literature for chlorophyllspecific absorption at this wavelength, which is often less than $0.02 \mathrm{~m}^{2}$ ( $\left.\mathrm{mg} \mathrm{chl} \mathrm{a)}\right)^{-1}$ (see table of values in Bricaud \& Stramski 1990). Moore et al. (1995) have suggested that the filter technique may overestimate the absorption coefficient in samples dominated by prochlorophytes. The errors in estimated absorption coefficient (computed using the path-length correction factor for Prochlorococcus marinus from Moore et al. 1995) increase with the measured optical density of the sample on filter. We estimate that, for our measurements, this could lead to a maximum overestimate of $16 \%$ in the red for the sample with the highest measured optical density, if that sample were made up entirely of pro-chlorophytes. This is not sufficient to explain our high specific absorption values in the red. It is possible that these high absorption coefficients reflect the combin-ed influences of low package effect and relatively high contributions from chl $b$-like pigments to absorption at $676 \mathrm{~nm}$. Indeed, high-performance liquid chromatography (HPLC) results obtained by Kraay (unpubl. data) during the same cruise revealed high chl b:chl a ratios $(0.155 \pm 0.056, \mathrm{n}=19)$ for samples from the Somali Current area and the Gulf of Aden.

The mean height of the chl a normalised Gaussian peak height at $676 \mathrm{~nm}$ is $0.028 \mathrm{~m}^{2}(\mathrm{mg} \mathrm{chl} \mathrm{a})^{-1}$, suggesting that even at this wavelength other pigments are responsible for some $12 \%$ of total absorption, on an average. But this is much smaller than the contribution at $435 \mathrm{~nm}$ : a similar comparison between total phytoplankton absorption and the Gaussian peak height at $435 \mathrm{~nm}$ suggests that the contribution from other pigments to absorption at this wavelength amounts to some $28 \%$ on the average.

\section{Flattening effect}

When the absorption spectrum is decomposed into Gaussian bands representing absorption by each of the major pigments, changes in peak heights associated with a single pigment can be studied. By virtue of its smaller magnitude, the red absorption peak due to chl a should be less affected by the flattening effect than the blue peak. Therefore, relative changes in the chl a peak height in the blue part of the spectrum (with a nominal band centre at $435 \mathrm{~nm}$ ) compared with the red peak (at around $676 \mathrm{~nm}$ ) should be an indicator of the importance of the flattening effect. Note that, since 


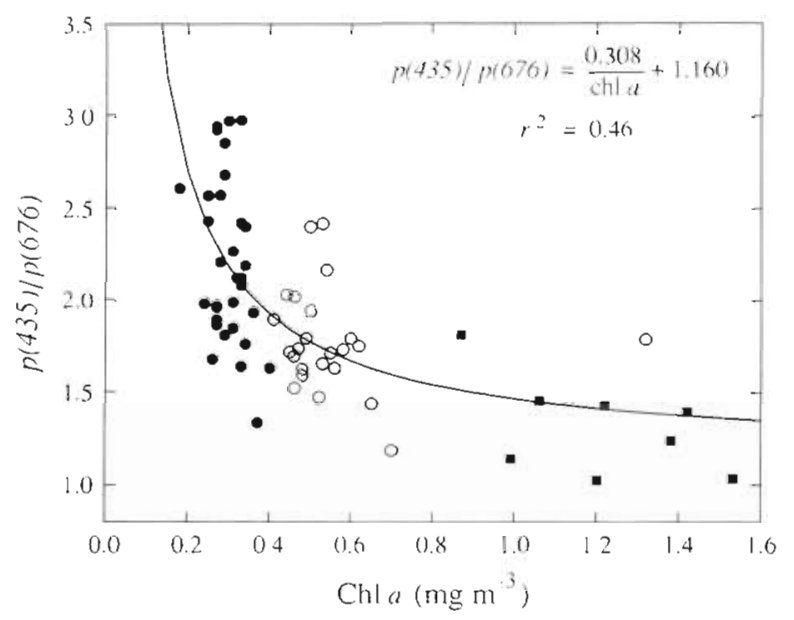

Fig. 5. Ratio of Gaussian peak height at $435 \mathrm{~nm}$ to Gaussian peak height at $676 \mathrm{~nm}$ as a function of chl a concentration, for the Somali Current area (•), Gulf of Aden (o) and the Red Sea (a)

we are taking the ratio of 2 bands associated with chlorophyll, the result is independent of chl a concentration. The ratio of the height of the blue peak to that in the red part of the spectrum is plotted in Fig. 5 as a function of chl a concentration. In this plot also, the 3 regions are fairly well separated, and the ratio of peak heights decreases from chlorophyll-poor waters to chlorophyll-rich waters, indicating that changes in phytoplankton population and cell size do modify the relative flattening effect in the blue part of the spectrum; one may also infer from the figure that the cell size (or the intracellular concentration of pigments) increases with chlorophyll concentration.

Unlike Fig. 4 , in which the abscissa and ordinate are not independent of each other, the axes are independent in this figure. The relationship between chl a concentration and the ratio of peak heights can be used to predict changes in the shape of the absorption spectrum in these waters from chl a concentration, which is easily measured, both by in situ techniques, and by remote sensing.

\section{Effect of changes in pigment composition}

Since the Gaussian bands separate the contributions from individual pigments to total absorption coefficient, they could also be used to study the role of pigment composition. In Fig. 6 we have plotted the chl $c$ peak height in the red part of the spectrum (nominal band centre at $644 \mathrm{~nm}$ ) as a function of chl a peak height, also in the red. Since the flattening effect appears to be relatively small for this chl a band, we may assume that this would also be true at $644 \mathrm{~nm}$,

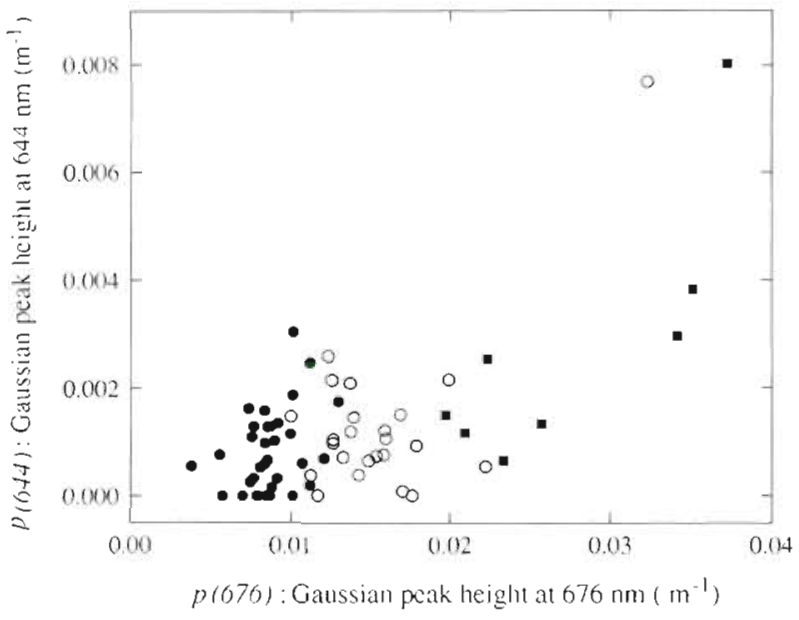

Fig. 6. Gaussian peak height at $644 \mathrm{~nm}(\mathrm{chl} c)$ as a function of Gaussian peak height at $676 \mathrm{~nm}$ (chl a) for the Somali Current area ( $\bullet$ ), the Gulf of Aden (o) and the Red Sea ( $\bullet$ )

where the absorption is lower than at $676 \mathrm{~nm}$. The figure shows that the chl $c$ peak height stays relatively small even when chl a peak height increases, except in the Red Sea. This is consistent with the presence of diatoms in these waters, which contain high concentrations of chl c (Rowan 1989).

\section{Characteristics of photosynthesis}

The $P-I$ parameters measured during this cruise showed a high degree of variability: the dynamic range in $\alpha^{B}$ was 3.7 around a mean value of $0.080 \mathrm{mg}$ $\mathrm{C}(\mathrm{mg} \mathrm{chl} \mathrm{a})^{-1} \mathrm{~h}^{-1}\left(\mathrm{~W} \mathrm{~m} \mathrm{~m}^{-2}\right)^{-1}$ [equivalent to $0.019 \mathrm{mg} \mathrm{C}$ ( $\mathrm{mg} c h l a)^{-1} \mathrm{~h}^{-1}$ (umol quanta $\left.\mathrm{m}^{-2} \mathrm{~s}^{-1}\right)^{-1}$ ), and the range in $P_{m}^{B}$ was 3.9 , around a mean value of $5.47 \mathrm{mg} \mathrm{C}(\mathrm{mg}$ chl a) ${ }^{-1}$. Variations with region and with depth (see Table 2) are not as clear-cut as in the case of absorption data.

Based on theoretical considerations, Sathyendranath \& Platt (1994) suggested that modifications in the photosynthetic rates of phytoplankton, in response to changing environmental conditions in general and to nutrient concentrations in particular. may play an important role in determining the occurrence of blooms in the Arabian Sea. There also is some evidence from field data in the $N$ Atlantic (Falkowski et al. 1985, Cleveland et al. 1989, Platt et al. 1992) that, in natural environments, $\alpha^{B}$ is modified by the availability of nitrate, though others (eg Marra et al. 1995) have suggested that it is not necessary to invoke such changes to model observed primary production in oligotrophic and nutrient-rich waters. 
Even if nutrient-dependent changes in $P-J$ parameters are important in the marine environment, it may be difficult to obtain direct evidence for it. First, concentrations of nutrients measured at the time of the $P-I$ experiment may not reflect either the rate of nutrient supply, or the history of nutrient availability. Secondly, changing nutrient concentrations may promote changes in the phytoplankton population, and different phytoplankton species may have varying responses to the same stimuli.

By definition, $\alpha^{B}$ is related in a linear fashion to specific absorption coefficient of phytoplankton. But, is there any reason to expect that $\alpha^{B}$ (or $P_{m}^{B}$ ) estimated for broadband illumination would be related to changes in the spectral shape of absorption? Our data on the spectral characteristics of light absorption by phytoplankton suggest that they contain some information on phytoplankton population structure and on their state of photoadaptation. If we now postulate that the different populations or a given population in different physiological states may indeed be photosynthesising at different rates, then it may be expected that the $P-I$ parameters may be related to changes in the spectral shape of light absorption by phytoplankton.

In this section we first examine the direct relationships between $\alpha^{B}$ and nitrate and compare the results with similar data from the $\mathrm{N}$ Atlantic from Platt et al. (1992). We then go on to explore whether changes in $P-I$ parameters are indeed related to spectral characteristics of light absorption by phytoplankton.

Dependence of $\alpha^{B}$ on nitrate: comparison with the North Atlantic

Platt et al. (1992) reported changes in $\alpha^{B}$ with changes in $\mathrm{NO}_{3}$ at a time-series station in the $\mathrm{N}$ Atlantic, during the declining phase of the Spring bloom in 1990. We fitted a Michaelis-Menten-type equation with an intercept to their data (Fig. 7a) which yielded:

$$
\alpha^{B}=0.0244+\frac{0.121 N}{(0.596+N)}
$$

where $N$ is nitrate concentration (mg-at. $\mathrm{N} \mathrm{m}^{-3}$ ). The equation fitted to the $N$ Atlantic data is not inconsistent with the Indian Ocean data (Fig. 7b); however, the data for the Indian Ocean are too noisy to have any predictive value. The $\mathrm{N}$ Atlantic spring bloom samples were comprised mainly of large diatoms and Phaeocystis cells (Head \& Horne 1993), whereas our samples con-

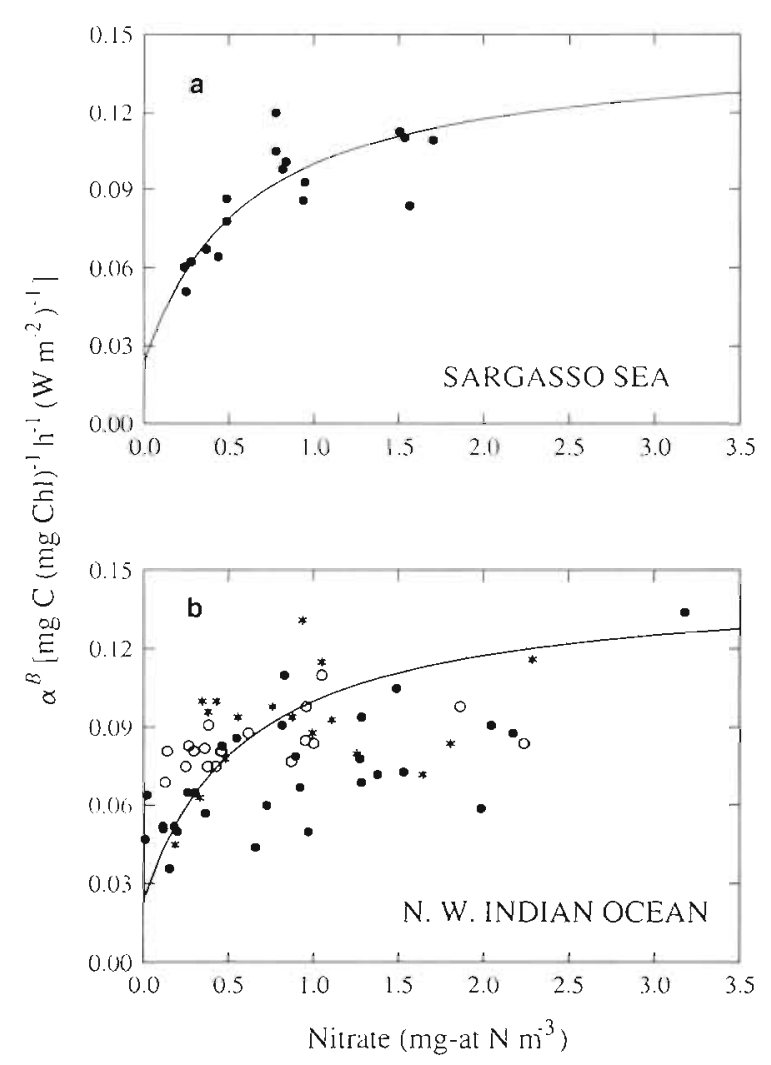

Fig. 7. The initial slope of the photosynthesis-light curve normalized to chl a concentration $\left(\alpha^{B}\right)$ as a function of nitrate concentration (a) for 0 to $40 \mathrm{~m}$ from the Sargasso Sea (data from Platt et al. 1992) and (b) for the NW Indian Ocean (present study) at 3 different sampling depths: $4 \mathrm{~m}(\bullet), 10 \mathrm{~m}(0)$ and $40 \mathrm{~m}(*)$ 
tained a diverse assemblage of small and large cells, the composition of which varied according to region. (see Table 1). This may account for some of the scatter in our data.

As can be seen from Fig $7 \mathrm{~b}$, there is some grouping according to depth of sampling, suggesting that the phytoplankton were adapting faster than they were mixing, which is also suggested by the absorption data. We next used absorption and other environmental data to examine whether the predictability of $P-I$ parameters could be improved using such information.

Prediction of $P_{m}^{B}$ and $\alpha^{B}$ from absorption characteristics and environmental co-variables

For application in modelling studies, it is often useful to be able to predict $P-I$ parameters from variables that are more easily measured, and for which better information bases exist. Measurements of phytoplankton absorption spectra are becoming routine on oceanographic cruises; futhermore, the ocean-colour signal accessible to remote sensing is a function of the absorption coefficient, and there is a possibility of retrieving phytoplankton absorption spectra from multi-spectral, remote measurements of ocean colour (Lee 1994). Being able to relate $P-I$ parameters to phytoplankton absorption characteristics would, in principle, alleviate the problem of extrapolating a small number of $P-I$ measurements to large scales (Sathyendranath \& Platt 1993) for use in computations of primary production from remotely sensed data.

In our analysis, we first examined linear relationships between the $2 P-I$ parameters and various characteristics of phytoplankton that contained useful information on phytoplankton size structure, its species composition and its response to the light environment. That is to say, we explored the relationships between the photosynthetic parameters and the absolute peak heights of chl $a$, the peak heights of chl a relative to total absorption at the wavelengths of peak maxima, the peak heights of chl a relative to peak heights of other pigments and specific absorption coefficients at wavelengths of maximum chl a absorption. We present here only the relationships that yielded the best results (maximum correlation coefficient for 5 or fewer independent variables). We also examined whether the predictability of $P-I$ parameters based on absorption could be improved further by including nutrients and the light levels at the sampling depth

We found that some $64 \%$ of the variance in $\alpha^{B}$ is explained by variations in the specific absorption of chl $a$ in the blue, $a_{c}^{*}(435)$, and red, $a_{c}(676)$, and the
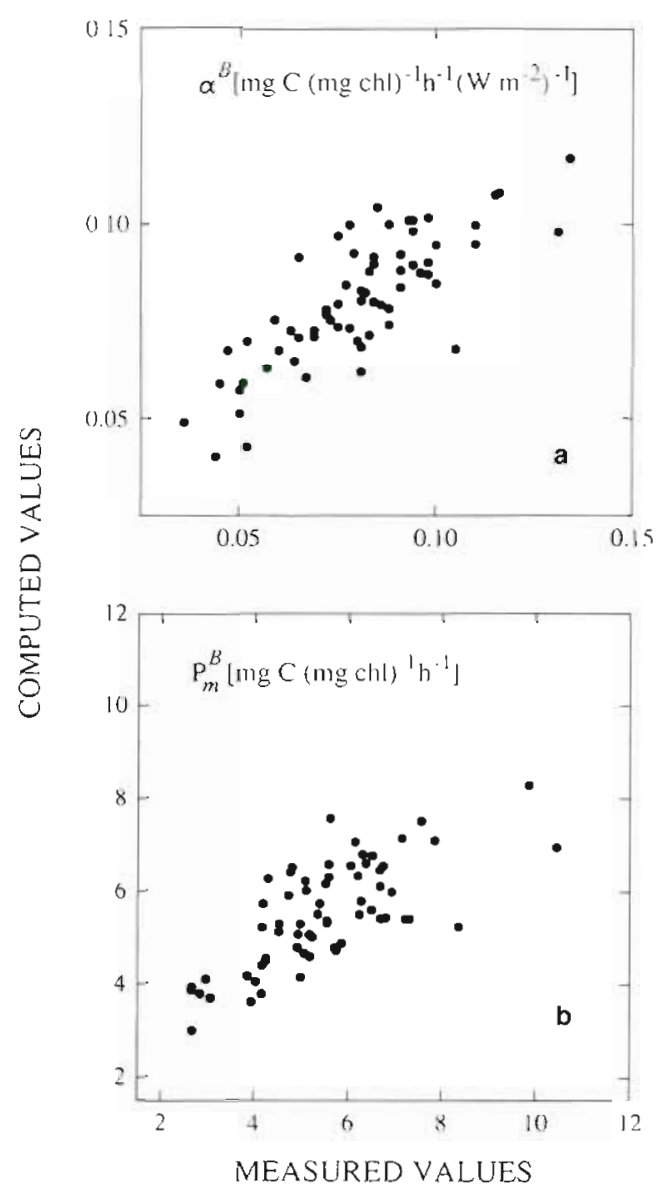

Fig. 8. Computed versus measured values of (a) $\alpha^{B}$ calculated from the multiple regression equation $\alpha^{B}=0.0375$ $1.09 a_{c}^{*}(435)+4.33 a_{c}^{*}(676)-0.841 p(676)$ and $(b)$ the assimilation number, $P_{m}^{B}$ calculated from the multiple regression equation $P_{m}^{B}=-2.20+113.3 a_{c} \cdot(435)+0.071 I_{z}-0.0011\left(I_{z}\right)^{2}-$ $169.10 \bar{a}_{c}^{*}+11.1 P$ (where $P$ is phosphate in $\mathrm{mmol} \mathrm{m}^{-3}$ )

Gaussian peak height at $676 \mathrm{~nm}, p(676)$ (Fig. 8a). All 3 properties are related to absorption maxima for chl a. However, the fact that both the red and blue peaks have to be used probably reflects the indirect effect of auxiliary pigments and package effect. The 2 specific absorption coefficients at 435 and $676 \mathrm{~nm}$ together explain some $59 \%$ of the total variance. Adding the chl a peak height at $676 \mathrm{~nm}$ had a small (but statistically significant) effect and increased the $r^{2}$ value by some $5 \%$. Note that $p(676)$ is not normalized to chl a concentration and therefore includes the effect of changing pigment concentration on total light absorption by phytoplankton. The negative coefficients associated with $a_{c}^{*}(435)$ and $p(676)$ suggest that high values of $\alpha^{B}$ are associated with low specific absorption coefficient in the blue and with low biomass. However, high specific absorption coefficient at $440 \mathrm{~nm}$ is in fact associated with low biomass in our data (see 
Fig. 4), which could be why there are no well-defined regional patterns in the distribution of $P-I$ parameters. These are tentative explanations of a rather complex result. Further interpretation would be tenuous at best and has to await more data and a better insight into how various phytoplankton populations in the natural environment respond to changes in environmental conditions.

Including nitrates or phosphates would account only for an additional 3 to $5 \%$ of the variance in $\alpha^{B}$, in this linear multiple regression. In our data, phosphate and nitrate were correlated, with an $r^{2}$ of 0.7 Given that there is evidence to suggest the relationship between $\alpha^{B}$ and nitrate is non-linear (see Fig. 7 ), this small contribution to a multiple linear regression is admittedly not a realistic representation of its full influence. However, we felt that the data (Fig. 7 b) were too noisy to attempt a non-linear regression.

The assimilation number is known to be determined by the dark reactions of photosynthesis, unlike $\alpha^{B}$. which is directly related to photochemical reactions Therefore, any relationship between $P_{m}^{B}$ and light absorption would have to be indirect at best. In fact, the specific absorption of chl $a$ in the blue, $a_{c}^{*}(435)$, and the mean specific absorption over the range 400 to $700 \mathrm{~nm}, \bar{a}_{c}^{*}$, together explain only some $18.7 \%$ of the total variance in $P_{m}^{B}$. Addition of the light available at the sampling depth, both $I_{z}$ and $\left(I_{z}\right)^{2}$, and $\mathrm{PO}_{4}$ $\left(\mathrm{mmol} \mathrm{m}^{-3}\right)$ as independent variables in the multiple linear regression increased the explained variance to $52 \%$ (see Fig. 8 b).

According to these results, there is hope that some information on variations in $\alpha^{B}$ could be derived from light absorption spectra of phytoplankton, which are in turn potentially accessible to remote sensing. This would certainly be an aid in remote sensing of primary production at large scales: assignment of parameter values for $P-I$ curves on a grid-by-grid basis for use in primary production calculations at the global scale is one of the pressing problems in this field. The approach appears to work less well for the second photosynthetic parameter that was measured, $P_{m}^{B}$. The computation of both the parameters can be improved if nutrient information could be provided as well. While these preliminary results are encouraging, we have to await data from other localities and other seasons to determine the extent of their validity.

\section{Quantum yield of photosynthesis}

The realised, maximum quantum yield of photosynthesis, $\phi_{m}$, is the ratio of the biomass-specific initial slope of photosynthesis, $\alpha^{B}$, to the specific absorption coefficient of the phytoplankton population (Platt \&
Jassby 1976). For a given wavelength, we have, by definition:

$$
\alpha^{B}=\phi_{m} a_{c}
$$

Models based on absorbed light rather than available light require information on both the quantities on the right hand side of Eq. (2), but estimates of $\phi_{m}$ are often lacking, and one is obliged to assume that this quantity is a stable property of natural, marine environments. This is especially true of computations in a remotesensing context, where the absorption properties of phytoplankton would be directly accessible from satellite data. In Fig. 9 we present $\alpha^{B}$ as a function of $\bar{a}_{c}^{*}$ the specific absorption coefficient for phytoplankton averaged over the entire spectral range from 400 to $700 \mathrm{~nm}$. Clearly, there is no simple, linear relationship between the 2 variables for the NW Indian Ocean data.

Even though we do not have spectrally resolved measurements of $\alpha^{B}$, our observations are sufficient for estimation of the maximum, realised quantum yield for 'white-light' conditions. We computed the maximum quantum yield [mol C (mol quanta) ${ }^{-1}$ ] as follows:

$$
\phi_{m}=0.00503 \frac{\alpha^{B}}{\bar{a}_{c}^{*}}
$$

where the constant converts grams to moles, hours to seconds and watts to moles of quanta, assuming $1 \mathrm{~W}=$ $4.6 \mu \mathrm{mol}$ quanta $\mathrm{s}^{-1}$ Values of $\phi_{m}$ varied from 0.0046 to $0.028 \mathrm{~mol} \mathrm{C}$ (mol quanta $)^{-1}$ (mean $\left.=0.014\right)$, a dynamic range of 6 , which is greater than the range in $\alpha^{B}$. These values are similar to quantum yields measured by Kishino et al. (1986) off Japan, for samples taken near the surface [0.005 to $\left.0.033 \mathrm{~mol} \mathrm{C} \mathrm{(mol} \mathrm{quanta)})^{-1}\right]$, using similar methods to measure $a_{c}^{*}$. They obtained values up to $0.094 \mathrm{~mol} \mathrm{C}$ (mol quanta) ${ }^{-1}$, close to the theoretical maximum of $0.1 \mathrm{~mol} \mathrm{C}$ (mol quanta) ${ }^{-1}$, for sam-

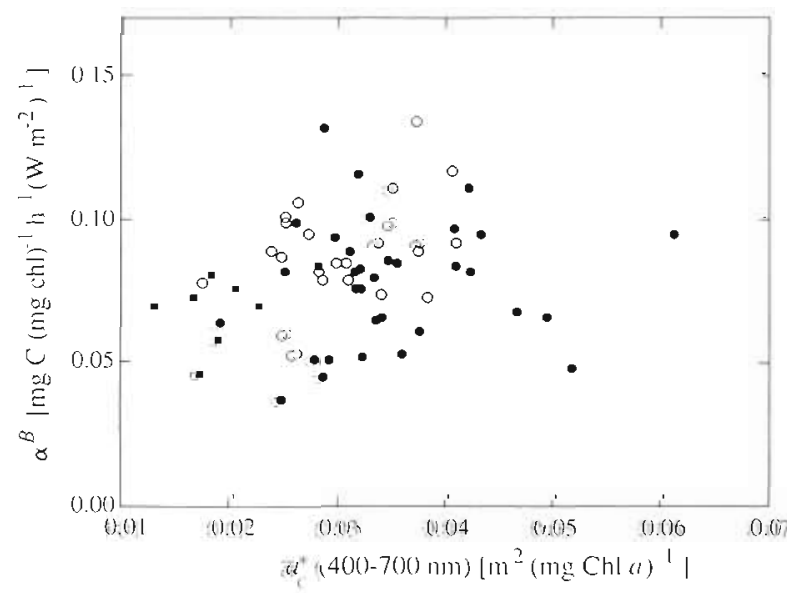

Fig. 9. $\alpha^{5}$ as a function of the specific absorption coefficient of phytoplankton averaged over the range 400 to $700 \mathrm{~nm}$, for the Somali Current area ( $\bullet$ ), the Gulf of Aden (0) and the Red Sea (-) 
ples from the subsurface chlorophyll maximum, but our observations did not extend below the mixed layer. On the other hand, Schofield et al. (1993) obtained a regional average of $\phi_{m}$ for the Southern California Bight of $0.027 \mathrm{~mol} \mathrm{C}$ (mol quanta) ${ }^{-1}$, which is close to the high end of our range. Other studies for natural communities (using a variety of methods) report $\dot{\phi}_{m}$ values that range from 0.03 to $0.07 \mathrm{~mol} \mathrm{C} \mathrm{(mol} \mathrm{quanta)}{ }^{-1}$ (Bannister \& Weidemann 1984), 0.03 to $0.1 \mathrm{~mol} \mathrm{C} \mathrm{(mol}$ quanta) ${ }^{-1}$ (Cleveland et al. 1989) and 0.02 to $0.07 \mathrm{~mol} \mathrm{C}$ (mol quanta $^{-1}$ (Babin et al. 1993). Many recent studies also report that $\phi_{m}$ values are highly variable in time and space (with a dynamic range of approximately 10), and are often 2 - to 10 -fold lower than the theoretical upper limit. (Prézelin et al. 1991, Bidigare et al. 1992, Schofield et al. 1993).

Cleveland et al. (1989) estimated apparent quantum yield by computing the ratio of $\alpha^{B}$ to total absorption by particulate matler and suggested that the contribution from nonphotosynthetic particles (such as phaeopigments or detritus) to absorption by particulate matter could be significant and may be responsible for apparent decreases in quantum yield.

They suggested that high values in the ratios of absorption at 435 to $676 \mathrm{~nm}$ would indicate the presence of nonphytoplanktonic, blue-light-absorbing particles. In fact, they found that the apparent quantum yield did indeed decrease with an increase in the value of this ratio. Their conclusions were further supported by the observations that the field samples had higher blue-to-red absorption ratios compared with healthy laboratory cultures.

Our estimates of quantum yield also show a tendency to decrease with increase in the value of $a_{c}(435): a_{c}(676)$ (Fig. 10a), even though our absorption data have been corrected for some detrital contribution. Samples were not corrected for phaeopigment but HPLC data showed phaeopigments concentrations to be negligible (Kraay unpubl. data). According to Cleveland et al. (1989), healthy laboratory cultures exhibit a range of $a_{c}(435): a_{c}(676)$ from 1.1 to 2.5 , which is similar to the range of our data (Fig. 10a). Only surface $(4 \mathrm{~m})$ samples from the Somali Current area showed any sign of enhanced blue absorption, with ratios greater than 2.5 .

When quantum yield is plotted against the ratio of Gaussian peak heights at 435 to $676 \mathrm{~nm}, p(435)$ : $p(676)$, instead of $a_{c}(435): a_{c}(676)$, we find that the trends are similar in both the cases (Fig, 10b). Since the changes in the $p(435): p(676)$ ratio may be interpreted (Fig. 5) as reflecting changes in the phytoplankton population and their state of photoadaptation, we are led to postulate that it is these changes that also govern some of the changes in quantum yield observed in our data.

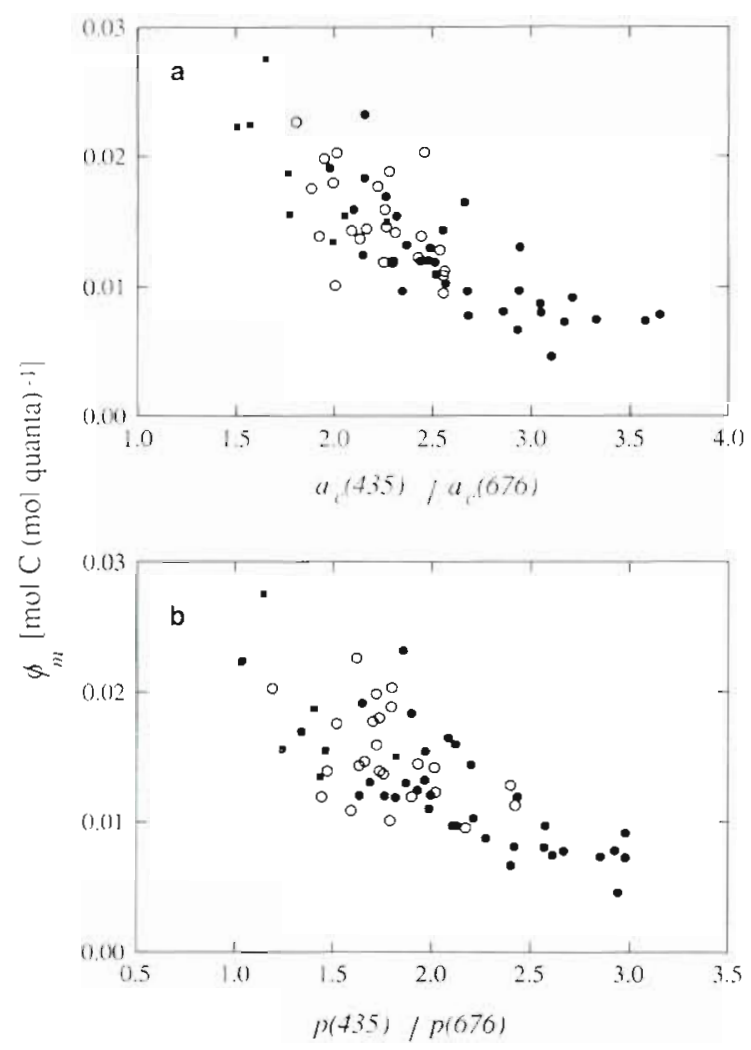

Fig. 10. Maximal quantum yield as a function of $(a)$ the ratio of absorption at $435 \mathrm{~nm}$ to absorption at $676 \mathrm{~nm}$ and (b) the ratio of the Gaussian peak height at $435 \mathrm{~nm}$ to the peak height at $676 \mathrm{~nm}$, for the Somali Current area (-), the Gulf of Aden (o) and the Red Sea (a)

Even though our samples are all from the mixed layer, the Somali Current area showed a depth-dependent increase in $\phi_{m}$, with surface samples having the lowest quantum yields [mean $0.0082 \mathrm{~mol} \mathrm{C}$ (mol quanta $\left.)^{-1}\right]$ compared with the 10 and $40 \mathrm{~m}$ samples [0.0130 and $0.0166 \mathrm{~mol} \mathrm{C} \mathrm{(mol} \mathrm{quanta)}{ }^{-1}$, respectively]. This depth-dependent increase in $\phi_{m}$ has been observed in several field studies (Dubinsky et al. 1984, Kishino et al. 1986) and may be due to an accumulation of blue-absorbing, photoprotective pigments in surface waters (see Dubinsky et al. 1986). There is some evidence for this in the shape of the absorption spectra from the Somali Current area (Fig. 3). In addition, Bidigare et al. (1989) found that zeaxanthin (which functions as a photoprotective pigment in cyanobacteria) could produce a 20 to $40 \%$ reduction in the quantum yield of Synechococcus spp. in the 425 to $500 \mathrm{~nm}$ spectral region (the wavelengths of maximum zeaxanthin absorption) and that the cellular zeaxanthin content increased with irradiance levels of blue-green light. From the limited HPLC data available (Kraay unpubl. data), samples from the Somali Current area showed higher zeaxanthin-to-chl a ratios $(0.194 \pm 0.044, n=12)$ 


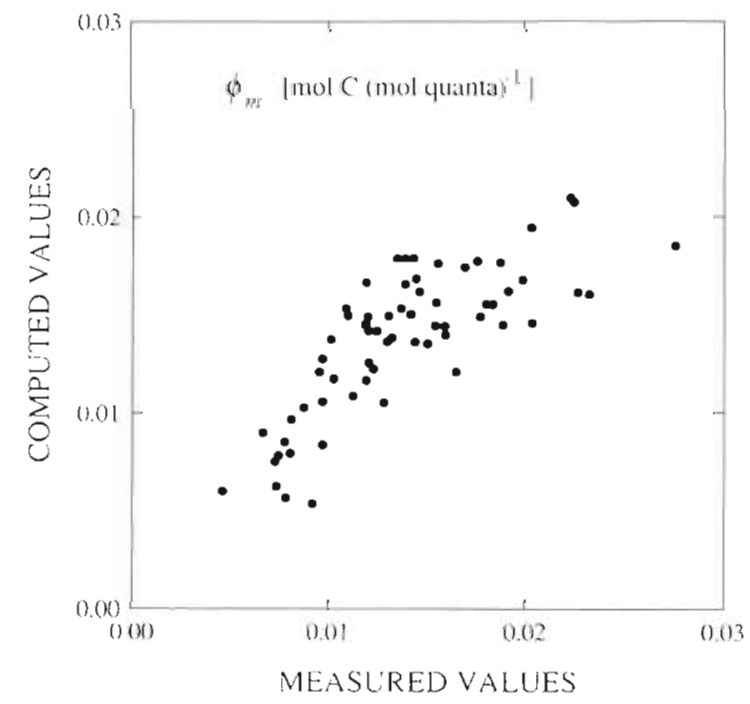

Fig. 11. Computed vs measured values of the maximal quantum yield, $\phi_{m}$, calculated using the multiple regression equation $\phi_{m}=4.44-0.00010\left(I_{l}\right)-1.12[p(435 / p(676)]+2.05 P$, where $P$ is phosphate concentration in $\mathrm{mmol} \mathrm{m}^{-3}$

than samples from the Gulf of Aden $(0.135 \pm 0.0818, n$ $=7$ ) or the Red Sea $(0.0224, n=1)$, suggesting that photoprotective pigments such as zeaxanthin may be partly responsible for the lower quantum yields in the Somali Current area.

The high absorption coefficients and reduced quantum yields in the Somali Current area samples could also be attributed to a reduced chl a content per cell as a result of photoadaptation (Cullen et al. 1993), which would in turn decrease the flattening effect and increase specific absorption (Johnsen \& Sakshaug 1993). The maximum quantum yield $\left(\phi_{m}\right)$ is thus highly variable and may be influenced by cell size and species composition as well as other physical and environmental factors such as mixing and ambient light levels. Clearly, for these conditions, it would not be suitable to treat $\phi_{m}$ as a constant for computing $\alpha^{B}$ from $\bar{a}_{i}$.

We examined the influence of environmental covariables on $\phi_{m}$, and a multiple linear regression of phosphate, $I_{z}$ and the ratio of chl a peak heights at $435 \mathrm{~nm}$ to that at $676 \mathrm{~nm}, p(435): p(676)$, was able to explain $62 \%$ of total variance in $\phi_{m}$ (see Fig. 11). Of this, the $p(435): p(676)$ ratio alone was responsible for some $56 \%$ of the variance, with the other 2 factors only explaining an additional $6 \%$.

\section{CONCLUSION}

The light absorption characteristics indicate some regional changes in the phytoplankton population, though these differences are not so apparent in the P-I data. It is probable that species-dependent changes would become evident in $\alpha^{B}$, if spectrally resolved data were available for this parameter. Models are now available that parameterise ocean colour and light penetration in the open ocean as functions of chl a concentration in the water (Morel 1988, Sathyendranath \& Platt 1988, 1989). These models assume that other optically active substances, such as the auxiliary pigments, covary with the chl a concentration. Deviations in pigment composition or size structure that might accompany changes in phytoplankton population are a source of noise in such models. The data presented in this paper, as well as data in a number of recent publications (Bricaud \& Stramski 1990, Hoepffner \& Sathyendranath 1993, Cleveland \& Perry 1994), have highlighted some of the systematic changes that accompany changes in species composition. Such information should eventually lead to optical models that allow explicitly for the consequences of changes in species composition. These results also highlight the need for improving the spectral resolution in satellite data on ocean colour so that changes in the shape of absorption spectra can be monitored (see Hoepffner \& Sathyendranath 1993, Lee 1994), rather than just the blue-green ratio, as in the case of the Coastal Zone Colour Scanner.

Brock et al. (1993) examined the relative importance of production in the mixed layer and in the deepchlorophyll maximum using a photosynthesis-light model and suggested that the production below the mixed layer could become important during oligotrophic, inter-monsoon periods. They pointed out that one of the limitations of the study was lack of information on $P_{-} I$ parameters from this region, which precluded accounting for the effects of nutrients and photoadaptation on $\alpha^{B}$ and $P_{m}^{B}$ (see also Banse 1994). The results presented in our paper are a step towards bridging this information gap. While some useful empirical relationships between the $P-I$ parameters and environmental co-variables have emerged, one has to await data from other seasons and regions of the NW Indian Ocean and from below the mixed layer to establish the limits of applicability of these relationships.

It has been suggested (Sathyendranath \& Platt, 1994), based on theoretical arguments, that changes in the $P-I$ parameters in response to changes in the availability of nutrients might play an important role in the initiation of blooms in the Arabian Sea. The results presented here show a 4 -fold variation in $\alpha^{B}$ related at least partially to changes in nitrate concentrations. But other factors such as changes in species composition could also be important. Although comparisons with data from the $\mathrm{N}$ Atlantic show some similarities in the nitrate dependence of $\alpha^{B}$, we would need more data 
before conclusions could be drawn on the generality of these results.

Our data show that the maximum, realised quantum yield varies by a factor of 6 ; in addition, $\alpha^{B}$ is poorly correlated with the specific absorption coefficient for phytoplankton. Clearly, the application in this area of models of primary production that are based on absorbed light require independent information on quantum yield as well. Our results do not support the view that the maximum realised quantum yield o... can be taken to be a constant, even for a limited region of the ocean (see also Prézelin et al. 1991. Schofield et al. 1993). On the other hand, there is some indication that some of the variability in quantum yield is related to changes in the shape of the absorption of phytoplankton, which can potentially be monitored through satellites. But the generabity of these results and the details of the mechanism that underlie this dependence have yet to be established.

Acknowledgements. The work presented in this paper was supported, in part, by the Office of Naval Research; the National Aeronautics and Space Administration; the Department of Fisheries and Oceans, Canada; and the Department of National Defence, Canada. Additional support was provided by the Natural Sciences and Engineering Research Councll through Operating Grants to S.S. and T.P. Samples were obtained during leg B2 of the 'Monsoons and Pelagic Systems' project of the Netherlands Indian Ocean Programme. The programme was supported and organized by the Netherlands Marine Research Foundation (SOZ) of the Netherlands Organization for Scientific Research (NWO). We appreciate the assistance of the project leader, $M$. Baars, and the staff and crew of the RV 'Tyro' We thank M. Baars and 2 anonymous reviewers for their comments on the manuscript. This work was carried out as part of the: Canadian contribution to the Joint Global Ocean Flux Study.

\section{LITERATURE CITED}

Baars MA (ed) (1994) Monsoons and pelagic systems. Report on three cruises of RV Tyro in the Somali Current, the Gulf of Aden and the Red Sea during the southwest monsoon of 1992 and the northeast monsoon of 1993. National Museum of Natural History, Leiden

Babin M, Therriault JC, Legendre L, Condal A (1993) Variations in the specific absorption coefficient for natural phytoplankton assemblages: impact on estimates of primary production. Limnol Oceanogr 38:154-177

Bannister TT, Weidemann AD (1984) The maximum quantum yield of phytoplankton photosynthesis in situ. J Plankton Res 6:275-294

Banse K (1994) On the coupling of hydrography, phytoplankton, zooplankton, and settling organic particles offshore in the Arabian Sea. Proc Indian Acad Sci (Earth Planet Sci) 103:125-161

Banse K, McClain CR (1986) Winter blooms of phytoplankton in the Arabian Sea as observed by the Coastal Zone Color Scanner. Mar Ecol Prog Ser 34:201-211

Bidigare RR, Prézelin BB, Smith RC (1992) Bio-optical models and the problems of scaling. In: Falkowski PG, Woodhead
AD (eds) Primary productivity and biogeochemical cycles in the sea. Environmental Science Research, Vol 143. Plenum Press, New York, p 175-212

Bidıgare RR. Schofield O. Prézelın BB (1989) Influence of zeaxanthin on quantum yield of photosynthesis of Synechococcus clone WH7803 (DC2). Mar Ecol Prog Ser 56: $177-188$

Bidigare RR, Smuth RC, Baker KS, Marra J (1987) Oceanic primary production estimates from measurements of spectral irradiance and pigment concentrations. Global Biogeochem Cycles 1:171-186

Bricaud A, Stramski D (1990) Spectral absorption coefficlents of living phytoplankton and nonalgal biogenous matter: A comparison between the Peru upwelling area and the Sargasso Sea. Limnol Oceanogr 35:562-582

Brock JC, McClain CR, Luther $\mathrm{N} 1 \mathrm{E}$, Hay WW (1991) The phytoplankton bloom in the northwestern Arabian Sea during the southwest monsoon of 1979. J Geophys Res 96: 20623-20642

Brock JC, Sathyendranath S, Platt T (1993) Modeling the seasonality of subsurface light and primary production in the Arabian Sea. Mar Ecol Prog Ser 101:209-221

Brock JC, Sathyendranath S, Platt T (1994) A model study of seasonal mixed-layer primary production in the Arabian Sea. Proc Indian Acad Sci (Earth Planet Sci) 103:163-176

Cleveland JS, Perry MJ (1994) A model for partitioning particulate absorption into phytoplanktonic and detrital components. Deep Sea Res 41:197-221

Cleveland. JS, Perry MJ, Kiefer DA, Talbot MC (1989) Maximal quantum yield of photosynthesis in the northwestern Sargasso Sea. J Mar Res 47:869-886

Cullen JJ, Geider RJ, Ishizaka J, Kiefer DA, Marra J, Sakshaug E, Raven JA (1993) Toward a general description of phytoplankton growth for biogeochemical models In: Evans GT, Fasham MJR (eds) Towards a model of ocean biogeochemical processes. NATO ASI Senes I, Vol 10. Springer-Verlag, Berlin, p 153-176

Cullen JJ, Lewis MR (1988) The kinetics of algal photoadaptation in the context of vertical mixing. J Plankton Res 10: $1039-1063$

Dubinsky Z, Berman T, Schanz F (1984) Field expenments for in situ measurement of photosynthetic efficiency and quantum yield. J Plankton Res 6:339-349

Dubinsky Z, Falkowski PG, Wyman K (1986) Light harvesting and utilization by phytoplankton. Pl Cell Physiol 27: $1335-1349$

Duysens LNM (1956) The flattening of the absorption spectrum of suspensions, as compared to that of solutions. Biochim Biophys Acta 19:1-12

Falkowski PG, Dubinsky Z, Wyman K (1985) Growth-irradiance relationships in phytoplankton. Limnol Oceanogr 30 $311-321$

Falkowski PG, LaRoche J (1991) Acclimation to spectral irradiance in algae. J Phycol 27:8-14

Geider RJ (1993) Quantitative phytoplankton physiology: implications for primary production and phytoplankton growth. In: Li WKW, Maestrini SY (eds) Measurement of primary production from the molecular to the global scale. ICES Marine Science Symposia, Vol 197. International Council for the Exploration of the Sea, Copenhagen, $\mathrm{p}$ $52-62$

Geider RJ, Platt T, Raven JA (1986) Size depundence of growth and photosynthesis in diatoms: a sunthesis. Mar Ecol Prog Ser 30:93-104

Head EJH, Horne EPW (1993) Pigment transformation ind vertical flux in an area of convergence: in the Vorth Atlantic. Deep Sea Res II 40:329-346 
Hoepffner N, Sathyendranath S (1991) Effect of pigment composition on absorption properties of phytoplankton. Mar Ecol Prog Ser 73:11-23

Hoepffner N, Sathyendranath S (1992) Bio-optical characteristics of coastal waters: absorption spectra of phytoplankton and pigment distribution in the western North Atlantic. Limnol Oceanogr 37:1660-1679

Hoepffner N. Sathyendranath S (1993) Determination of the major groups of phytoplankton pigments from the absorption spectra of total particulate matter $J$ Geophys Res 98:22789-22803

Johnsen G, Sakshaug E (1993) Bio-optical characteristics and photoadaptive responses in the toxic and bloom-forming dinoflagellates Gyrodinium aureolum, Gymnodinium galatheanum, and two strains of Prorocentrum minimum. J Phycol 29:627-642

Kiefer DA, Mitchell BG (1983) A simple, steady state description of phytoplankton growth based on absorption cross section and quantum efficiency. Limnol Oceanogr 28: $770-776$

Kirk JTO (1976) A theoretical analysis of the contribution of algal cells to the attenuation of light within natural waters. III. Cylindrical and spheroidal cells. New Phytol 77: 341-358

Kishino M. Okami N, Takahashi M, Ichimura S (1986) Light utilisation efficiency and quantum yield of phytoplankton in a thermally-stratified sea. Limnol Oceanogr 31:557-566

Kishino M, Takahashi M, Okami N, Ichimura S (1985) Estimation of the spectral absorption coefficients of phytoplankton in the sea. Bull Mar Sci 37:634-642

Lee ZP (1994) Visible-infrared remote-sensing model and applications for ocean waters. PhD thesis, University of South Florida, St. Petersberg, p 145

Marra J, Heinemann KR (1987) Primary production in the North Pacific Central Gyre: some new measurements based on ${ }^{14} \mathrm{C}$. Deep Sea Res I 34:1821-1829

Marra J, Langdon C, Knudson CA (1995) Primary production, water column changes, and the demise of a Phaeocystis bloom at the Marine Light-Mixed Layers site $159^{\circ} \mathrm{N}$, $21^{\circ} \mathrm{W}$ ) in the northeast Atlantic Ocean. J Geophys Res 100:6633-6643

Mitchell BG, Kiefer DA (1984) Determination of absorption and fluorescence excitation spectra for phytoplankton. In Holm-Hansen O, Bolis L, Giles R (eds) Marine phytoplankton and productivity. Springer-Verlag, Berlin, 157-169

Mitchell BG, Kiefer DA (1988) Chlorophyll a specific absorption and fluorescence excitation spectra for light-limited phytoplankton. Deep Sea Res I 35:639-663

Moore LR, Goericke R, Chisholm SW (1995) Comparative physiology of Synechococcus and Prochlorococcus influence of light and temperature on growth, pigments, fluorescence and absorptive properties. Mar Ecol Prog Ser 116:259-275

Morel A (1988) Optical modeling of the upper ocean in relation to its biogenous matter content (Case I waters). J Geophys Res 93:10749-10768

This article was submitted to the editor
Morel A, Bricaud A (1981) Theoretical results concerning light absorption in a discrete medium, and application to specific absorption of phytoplankton. Deep Sea Res I 28A: $1375-1393$

Platt T, Gallegos CL, Harrison WG (1980) Photoinhibition of photosynthesis in natural assemblages of marine phytoplankton. J Mar Res 38:687-701

Platt T, Jassby AD (1976) The relationship between photosynthesis and light for natural assemblages of coastal manne phytoplankton. J Phycol 12:421-430

Platt T, Sathyendranath S, Ulloa O, Harrison WG, Hoepffner N, Goes J (1992) Nutrient control of phytoplankton photosynthesis in the Western North Atlantic. Nature 356: $229-231$

Prézelin BB, Tilzer MM, Schofield O, Haese C (1991) The control of the production process of phytoplankton by the physical structure of the aquatic environment with special reference to its optical properties. Aquat Sci 53: $136-186$

Rowan KS (1989) Photosynthetic pigments of algae. Cambridge University Press, Cambridge, p 334

Sathyendranath S, Gouveia AD. Shetye SR, Ravindran P, Platt T (1991) Biological control of surface temperature in the Arabian Sea. Nature 349:54-56

Sathyendranath S, Lazzara L, Prieur L (1987) Variations in the spectral values of specific absorption of phytoplankton. Limnol Oceanogr 32:403-415

Sathyendranath S, Platt $T$ (1988) The spectral irradiance field at the surface and in the interior of the ocean: a model for applications in oceanography and remote sensing. J Geophys Res 93:9270-9280

Sathyendranath S, Platt $T$ (1989) Remote sensing of ocean chlorophyll: consequence of non-uniform pigment profile. Appl Oplics 28:490-495

Sathyendranath S, Platt T (1993) Remote sensing of watercolumn primary production. In: Li WKW, Maestrini SY (eds) Measurement of primary production from the molecular to the global scale. ICES Marine Science Symposia, Vol 197 International Council for the Exploration of the Sea, Copenhagen, 236-243

Sathyendranath S, Platt $T$ (1994) New production and mixedlayer physics. Proc Indian Acad Sci (Earth Planet Sci) 103: $177-188$

Schofield O, Prézelin BB, Bidigare RR, Smith RC (1993) In situ photosynthetic quantum yield. Correspondence to hydrographic and optical variability within the Southern California Bight. Mar Ecol Prog Ser 93:25-37

Tilzer MM, Gieskes WW, Heusel R, Fenton N (1994) The impact of phytoplankton on spectral water transparency in the Southern Ocean: implications for primary productivity. Polar Biol 14:127-136

Yentsch CS (1962) Measurement of visible light absorption by particulate matter in the ocean. Limnol Oceanogr 7 : $207-217$

Yentsch CS (1965) Distribution of chlorophyll and phaeophytin in the open ocean. Deep Sea Res I 12:653-666

Manuscript first received: February 8, 1995

Revised version accepted: August 23, 1995 